\title{
Surgical Treatment of Grade IV Gynecomastia; No Vertical Scar Versus Circumareolar Scar Reduction Mammoplasty
}

\author{
SAMEH ELGHAMRY, M.D.; KAREEM ALSHARKAWY, M.D.; MOHAMED M. KHEDR, M.D.; \\ SHERIF A. HANTASH, M.D. and TAREK G. SHOUKR, M.D. \\ The Department of Plastic and Reconstructive Surgery, Faculty of Medicine, Tanta University, Tanta, Egypt
}

\begin{abstract}
Objectives: To compare between no vertical scar and circumareolar scar for surgical treatment of high-grade gynecomastia as regard patient satisfaction score.

Background: Surgical treatment is increasing in rate in the last few years; and aesthetic reconstructive surgery is increasingly desired in grade 3 and 4 of Gynecomastia, this study will help us to determine the best choice for our patients.

Methods: This is a prospective, comparative, randomized and descriptive study of 30 male patients suffering from enlargement of the breast size. The patients were divided into two groups; Group A subjected to no vertical scar technique (15 patients). Group B subjected to donut circumareolar technique (15 patients). Both groups were compared for patient satisfaction score.
\end{abstract}

Results: Using of donut circumareolar technique in comparison to no vertical scar technique leads to statistically significant post-operative patient satisfaction score.

Conclusion: Using of donut circumareolar technique has a beneficial effect on increasing patient satisfaction.

Key Words: Gynecomastia - Donut circumareolar technique - Vertical scar - Liposuction - Mastopexy Breast tissue reduction.

\section{INTRODUCTION}

Benign enlargement of the male breast is what is called gynecomastia. It negatively affects the psychosocial well-being of affected adolescent patients. Social functioning, mental health, and self-esteem are specifically affected by such condition [1].

Waltho and colleagues, 2017, systematically reviewed various classification systems and identified 10 breast characteristics that were included in the 11 classification systems that met their inclusion criteria. They included 4 common features namely; breast size, skin redundancy, breast ptosis and tissue predominance. The remaining features that were variably used by the studied classification systems included; upper abdominal laxity, breast tuberosity, nipple malposition, chest shape, absence of sternal notch and breast skin elasticity [2].

One of the oldest classification systems is that presented by Webester who has classified gynecomastia into glandular type, fatty glandular type and simply fatty type [3]. Gynecomastia can be classified into three grades: Grade I: Small visible breast enlargement and no skin redundancy, Grade IIA: Moderate breast enlargement without skin redundancy, Grade IIB: Moderate breast enlargement with skin redundancy, Grade III: Severe breast enlargement with marked skin redundancy according to morphology and degree of skin redundancy [4].

The American Society of Plastic Surgeons (ASPS) has adapted a classification system based on descriptive terms rather than quantitative [5]:

- Grade I: Small breast enlargement with localized button of tissue around the areola.

- Grade II: Moderate breast enlargement exceeding areola boundaries with indistinct edges from the chest.

- Grade III: Moderate breast enlargement exceeding areola boundaries with distinct edges from the chest and skin redundancy.

- Grade IV: Marked breast enlargement with skin redundancy and feminization of the breast.

Current surgical options are tailored to each grade of gynecomastia, hence a variety of technique that can be used solely or in combinations have evolved. These include liposuction, either conventional, power assisted or ultrasound assisted, pullthrough techniques, subcutaneous mastectomy and finally breast reduction techniques [6-9]. Achieving a good aesthetic outcome in patients with highgrade gynecomastia can be challenging. In this 
specific group of patients, patient's satisfaction is considered an essential measure of treatment success apart from objective aesthetic outcomes evaluation [10-12].

The aim of this study is to compare between the results of two surgical techniques of reduction mammoplasty: No vertical scar and circumareolar scar and the impact on patients satisfaction following surgical treatment of high grade gynecomastia (grade IV according to ASPS classification which is equivalent to grade III by Simon's classification).

\section{MATERIAL AND METHODS}

This is a prospective, comparative, randomized and descriptive study of 30 male patients suffering from high grade gynecomastia, conducted in the period from $1 / 6 / 2017$ to $1 / 12 / 2018$. The patients were divided into two groups undergoing breast reduction with one of two techniques; Group A subjected to no vertical scar technique (15 patients). Group B subjected to donut circumareolar technique (15 patients). Both groups were compared for patient's satisfaction score.

\section{Inclusion criteria:}

Patients (male) presented with severe breast tissue enlargement and marked redundancy in the skin.

\section{Exclusion criteria:}

Age less than 18 years and above 65 years, severe comorbidity interfering with anesthesia and uncontrolled Diabetes Mellitus (DM). All patients were subjected to the following:

Pre-operative work up:

Explanation and an informed consent before admission preserving all ethical considerations of the patients, the patient was informed about the location of the incision and placement of drains. Proper clinical evaluation of each case was done to exclude underlying factors (pharmacological or pathological). Relevant laboratory investigations were ordered accordingly. Also, breast ultrasound was done to exclude presence of abnormal mass.

\section{Marking and operative steps:}

Group A (Fig. 1): While in upright position the midline of the chest, inframammary fold, breast meridian (from the mid-clavicular point to the nipple normally $=18 \mathrm{~cm}$ ) were marked, and then with the patient lying down three concentric circles centered at the nipple were drawn.

Under general anesthesia with the patient in the supine position, prepping and draping were done followed by infiltration of the subcutaneous tissue with tumescent solution composed of 250$350 \mathrm{ml}$ mixture of normal saline $1000 \mathrm{ml}$, lidocaine $2 \% 25 \mathrm{ml}$, and $1 \mathrm{ml}$ adrenaline 1:1000 was carried out. In order not to jeopardize the vascularity of the nipple-areola complex meticulous deepithelialization between the inner and the outer circle was performed. Careful tailoring of this area to fit the degree of skin redundancy and the size of the breast for each patient should be done. Leaving $10-15 \mathrm{~mm}$ thickness of tissue on the undersurface of the nipple and areola and to the pectoral fascia deeply without insulting it, the gynecomastia structure with a decent amount of breast tissue was dissected from the nipple and areola through a semicircular incision at the lower edge of the large circle this was followed by proper hemostasis and negative suction drain was inserted. With the aid of a purse string proline $4 / 0$ suture through the large circle to fit the size of the small one, the wound was closed. Subsequently, deep dermal interrupted vicryl 4/0 sutureswere applied, followed by subcuticular skin closure using vicryl $5 / 0$ sutures. The excised tissue was sent for histopathological examination.

Group B (Fig. 2): Two horizontal lines were drawn at the level of the supra-sternal notch and at the center of the infra-mammary creases.

The distance between the two lines was measured. A point, having the same distance from the suprasternal plane was marked on the breast at the midclavicular line, point $\mathrm{A}$. This is the length of the upper flap and the inferior limit of the breast.

The medial and lateral limits of the breast were marked at the level of the infra-mammary crease, points $\mathrm{B}$ and $\mathrm{C}$ respectively. Point $\mathrm{C}$ was made slightly higher than point $\mathrm{B}$. Point $\mathrm{D}$ was marked on the infra-mammary crease in the same vertical plain as point A. An ellipse was marked, joining points $\mathrm{A}, \mathrm{B}, \mathrm{C}$ and $\mathrm{D}$.

The new nipple position was marked over the fourth intercostal space in the same vertical plain as the present one unless there was a need to transpose it horizontally, point E. A circular mark was drawn around the areola at the desired size.

Two dotted circles were drawn on the skin delineating the contour of the breast to determine the limits of the excision and feathering.

With the patient in the semi-sitting position and under general anesthesia, the operation was carried out. The points and lines are scored, and the breasts are infiltrated with diluted epinephrine, $1 / 200,000$. 

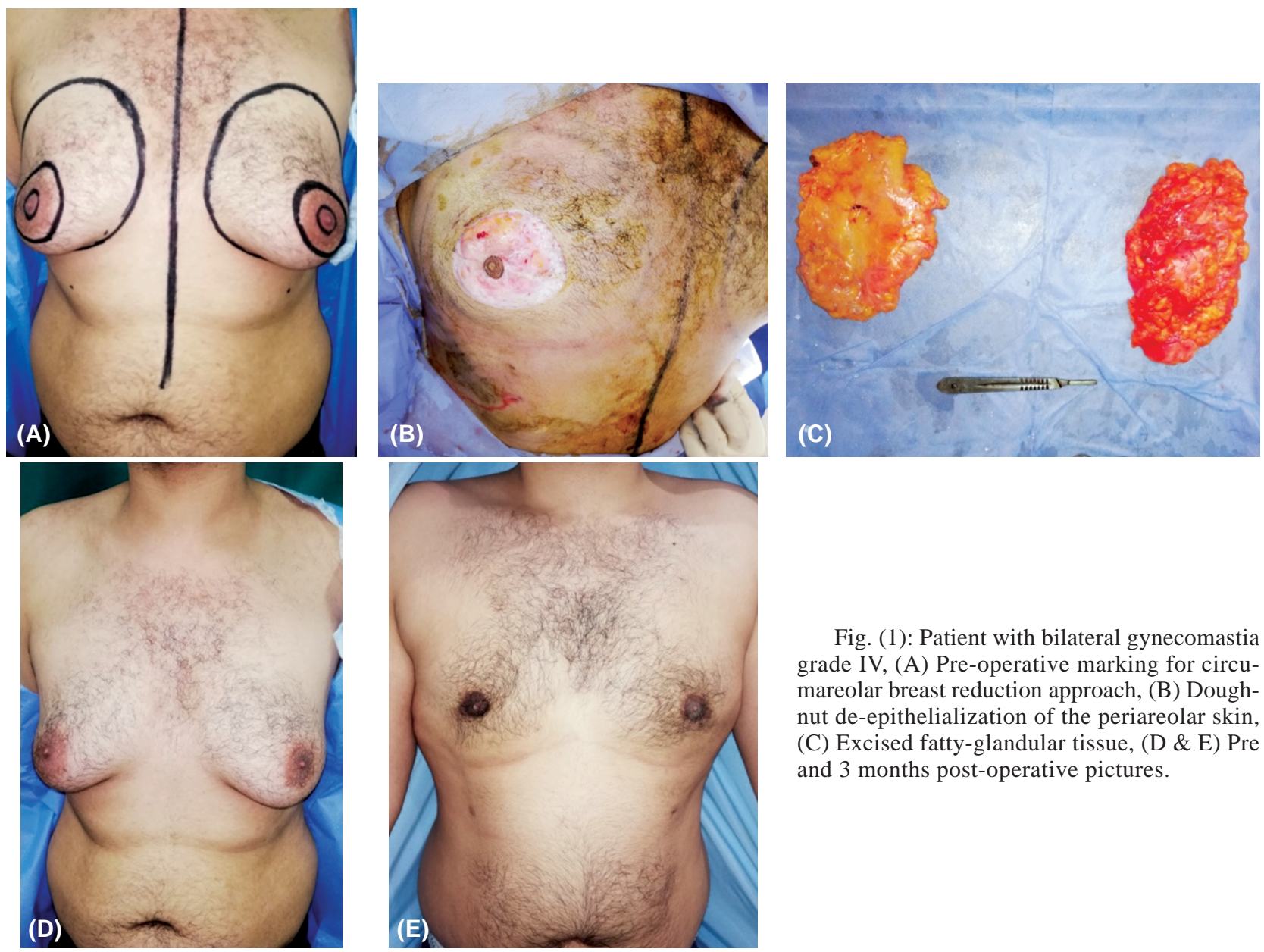

Fig. (1): Patient with bilateral gynecomastia grade IV, (A) Pre-operative marking for circumareolar breast reduction approach, (B) Doughnut de-epithelialization of the periareolar skin, (C) Excised fatty-glandular tissue, (D \& E) Pre and 3 months post-operative pictures.
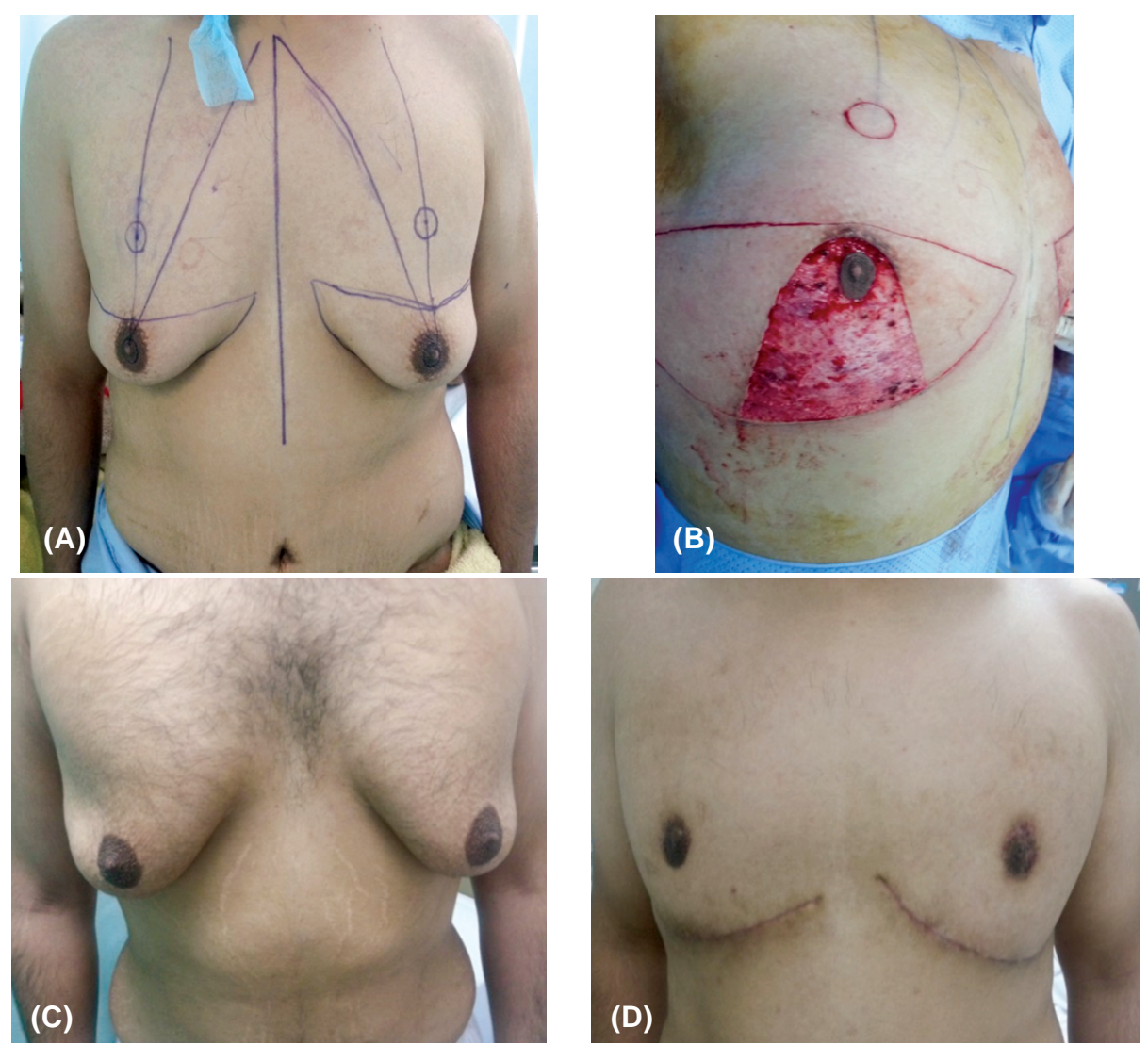

Fig. (2): Patient with bilateral gynecomastia grade IV, (A) Pre-operative marking for no vertical scar breast reduction approach, (B) Nipple areola preserved on a de-epithelialised inferior pedicle, (C,D) Pre and 3 months post-operative results. 
The area between points $\mathrm{ABC}$ and $\mathrm{D}$ is deepithelialized excluding the areola. This will be the lower dermo fascial flap.

The line BAC was incised down to and including the superficial fascia. All the breast tissue between the dermo-fascial layer and the pectoral fascia was removed with care not to disrupt the sensory nerves at the lateral part of the breast, creating the inferiorly based lower dermo-fascial flap. The excision was feathered at the margins, and the deep attachment of the infra-mammary crease was disrupted.

The upper flap was dissected as high as needed to excise all the remaining breast tissue and to allow fixing of the lower flap to the pectoral fascia. The thickness of the flaps could be increased proportional to the amount of the subcutaneous fat elsewhere in the chest to prevent saucer deformity or nipple inversion.

The lower flap was fixed to the pectoral fascia high under the upper flap by $2 / 0$ proline sutures. The transverse excess in the lower flap can be excised or tucked under the lateral margins of the upper flap to achieve smoothening of the contour. The upper flap was then sutured to the line BDC.

The nipples were exteriorized through the upper flap and sutured at their marked position. If there was difficulty in transposing the nipple in the transverse direction, a medial or lateral back cuts were made as desired to facilitate its movement. A3/0 burse-string prolene ${ }^{\circledR}$ sutures might be placed around the areolae but were not often necessary as there was no tension on the circumareolar sutures. After careful hemostasis, wound was closed in two layers. Drains were not usually needed, and compressive dressing was applied for a week to be followed by an elastic garment.

Both groups were compared as regard the demographics of the patients, volume of gland resected, time to drain removal, duration of hospital stay, post-operative complications and patient satisfaction score.

\section{Statistical analysis:}

The results had been collected, evaluated, calculated, tabulated and statistically analyzed using a computer statistical package (IBM SPSS Statistics for Windows, Version 21.0. Armonk, NY, USA: IBM Corp.) with a significant $p$-value $\leq 0.05 \%$.

\section{RESULTS}

There was no statistically significant difference in patients' demographics, age \& BMI (Table 1). The resected volume was significantly higher in group B undergoing the no vertical scar approach (Table 2). Also, time for drain removal and duration of hospital stay were significantly higher in group B. The patient satisfaction scores were significantly higher in group A undergoing the circumareolar approach (Tables $3,4)$. Complications in the form of seroma, asymmetry and wound dehiscence were more prevalent in group B 45\% than in group A 20\% (Table 5).

Table (1): Pre-operative data: Showing no significant difference between patient characteristics in each group.

\begin{tabular}{|c|c|c|c|}
\hline \multirow{2}{*}{$\begin{array}{l}\text { Comparative } \\
\text { pre-operative } \\
\text { features }\end{array}$} & \multicolumn{2}{|c|}{ Technique } & \multirow{2}{*}{$\begin{array}{c}p- \\
\text { value }\end{array}$} \\
\hline & $\begin{array}{c}\text { Group A } \\
\mathrm{N}=15\end{array}$ & $\begin{array}{c}\text { Group } B \\
\mathrm{~N}=15\end{array}$ & \\
\hline \multicolumn{4}{|l|}{ Age (years): } \\
\hline Range & $20-48$ & $25-55$ & 0.944 \\
\hline Mean & 35.29 .07 & 35.29 .57 & \\
\hline \multicolumn{4}{|c|}{ Body mass index: } \\
\hline Range & $19.1-39.3$ & $19.7-43$ & 0.152 \\
\hline Mean & $27.98 \pm 4.19$ & $26.63 \pm 4.72$ & \\
\hline
\end{tabular}

Table (2): Intra operative data.

\begin{tabular}{|c|c|c|c|c|}
\hline \multirow{2}{*}{$\begin{array}{l}\text { Comparative } \\
\text { intra-operative } \\
\text { features }\end{array}$} & \multicolumn{3}{|c|}{ Technique } & \multirow{2}{*}{$\begin{array}{c}p- \\
\text { value }\end{array}$} \\
\hline & \multicolumn{2}{|c|}{$\begin{array}{c}\text { Group A } \\
\mathrm{N}=15\end{array}$} & $\begin{array}{l}\text { Group B } \\
\mathrm{N}=15\end{array}$ & \\
\hline \multicolumn{5}{|l|}{$\begin{array}{l}\text { Resected part } \\
\text { weight (grams): }\end{array}$} \\
\hline Range & \multicolumn{2}{|c|}{$1350-3850$} & & \multirow[t]{2}{*}{$0.006 *$} \\
\hline Mean & \multicolumn{2}{|c|}{$2673.3 \pm 973$} & $3028 \pm 1068$ & \\
\hline \multicolumn{5}{|c|}{ Table (3): Post-operative data. } \\
\hline \multirow{2}{*}{\multicolumn{2}{|c|}{$\begin{array}{l}\text { Comparative } \\
\text { post-operative features }\end{array}$}} & \multicolumn{2}{|c|}{ Technique } & \multirow[b]{2}{*}{$\begin{array}{c}p- \\
\text { value }\end{array}$} \\
\hline & & $\begin{array}{c}\text { Group A } \\
\mathrm{N}=15\end{array}$ & $\underset{\mathrm{N}=15}{\text { Group } B}$ & \\
\hline \multicolumn{5}{|c|}{ Time of drain removal (days): } \\
\hline Range & & $2-5$ & $2-6$ & \multirow[t]{2}{*}{$0.0001^{*}$} \\
\hline Mean & & $3.7 \pm 1.42$ & $5.14 \pm 3.08$ & \\
\hline \multicolumn{5}{|l|}{ Hospital stay (days): } \\
\hline Range & & $3-16$ & 4-11 & \multirow[t]{2}{*}{$0.00026^{*}$} \\
\hline Mean & & $4.91 \pm 1.70$ & $6.8 \pm 3.24$ & \\
\hline \multicolumn{5}{|c|}{$\begin{array}{l}\text { Patient satisfaction score in } \\
\text { numbers: }\end{array}$} \\
\hline Range & & $3-5$ & $2-4$ & \multirow[t]{2}{*}{$0.00116 *$} \\
\hline Mean & & $4.1 \pm 0.841$ & $2.9 \pm 0.798$ & \\
\hline
\end{tabular}

Table (4): Patient's satisfaction sore.

\begin{tabular}{lccc}
$\begin{array}{l}\text { Post-operative } \\
\text { satisfaction }\end{array}$ & Group A & Group B & $\begin{array}{c}\text { No. of } \\
\text { patients }\end{array}$ \\
\hline Very dissatisfied & 0 & 0 & 0 \\
Dissatisfied & 0 & 0 & 0 \\
Average & 2 & 4 & 6 \\
Satisfied & 3 & 5 & 8 \\
Very satisfied & 10 & 6 & 16 \\
\hline
\end{tabular}


Table (5): Post-operative complications.

\begin{tabular}{lll}
\hline Complication & Group A & Group B \\
\hline Seroma & 0 & 3 \\
Partial dehiscence & 1 & 1 \\
Asymmetry & 2 & 3 \\
\hline Total number $(\%)$ & $3(20 \%)$ & $7(45 \%)$ \\
\hline
\end{tabular}

\section{DISCUSSION}

Physiologic gynecomastia will often regress spontaneously, as with withdrawal of an offending drug in drug-induced gynecomastia. However, most forms of grade III \& IV gynecomastia being idiopathic have only surgery as a gold standard treatment.

Surgery consists of a combination of liposuction and excisional techniques. A lot of debate exists among surgeons upon the techniques used, some of them advocating that liposuction should be the only treatment in all cases, regardless of the amount of parenchyma and excess skin, at least in the first stage, followed, if necessary, by a second stage of excess glandular excision or areola reduction (69 months after ultrasound-assisted liposuction to allow for maximal skin retraction) [13-15].

Most of the difficulties in the surgical treatment of the gynecomastia are due to the restrict size of the incision that prejudices the illumination of the operative field and the hemostasis. The transareolar mammary and infra-areolar marginal incisions are not always efficient to correct gynecomastia with marked skin redundancy and to elevate the nippleareola complex.

In the current study, we tried to explore the potentials of two different approaches in surgical treatment of grade IV gynecomastia and compare the patient satisfactions following them.

We found the no vertical scar technique provided better exposure and allowed larger volume of tissues to be resected with better hemostasis that permitted the earlier removal of drains and hence less hospital stay when compared to the circumareolar approach.

On the otherhand, the patients' satisfaction scores were significantly higher in the circumareolar approach group which could be attributed to the inconspicuous scar at the areola-skin junction.
Other methods of skin resections by means of inverted $\mathrm{T}$ technique result in long scars and can leave the breast cone like. The illness stigma is replaced by a scar stigma, especially in patients with hairless chest wall. The removal of the vertical component of such scare reduces the scare burden for patients [16]. In massive gynecomastia, the amount of skin to be removed is only limited by tension on digital pinching and by position of the areola. The patient should be advised about the possibility of a second-stage procedure to remove residual skin and adipose tissue. The redundant adipoglandular tissue in the inferior pole of the breast is credited to the fear of thinning excessively the base of the inferior pedicle flap.

\section{Conclusion:}

Circumareolar approach for surgical treatment of gynecomastia has a beneficial effect on decreasing scar formation, increase patient satisfaction, on the other hand it the no vertical scar techniques allows more tissues to be removed but offers better access reducing the time needed for drain removal and hospital stay, however the resulting scar and the residual fatty glandular tissue at the inferior pedicle leads to less patient satisfaction.

\section{REFERENCES}

1- Nuzzi L.C., Cerrato F.E., Erikson C.R., Webb M.L., Rosen H., Walsh E.M., et al.: Psychosocial impact of adolescent gynecomastia: A prospective case-control study. Vol. 131, Plastic and Reconstructive Surgery, p. 890-6, 2013.

2- Waltho D., Hatchell A. and Thoma A.: Gynecomastia Classification for Surgical Management. Plast. Reconstr. Surg., Mar., 139 (3): 638e-48e, 2017.

3- JP W.: Mastectomy for gynecomastia through a semicircular intra-areolar incision. Ann. Surg., 124 (3): 557-75, 1946.

4- Simon B.E., Hoffman S. and Kahn S.: Classification and surgical correction of gynecomastia. Plast. Reconstr. Surg., Jan., 51 (1): 48-52, 1973.

5- American Society of Plastic Surgeons: ASPS Recommended Insurance Coverage Criteria for Third-party Payers: Reduction mammoplasty, p. 1-6, 2017.

6- Cordova A. and Moschella F.: Algorithm for clinical evaluation and surgical treatment of gynaecomastia. J. Plast. Reconstr. Aesthetic Surg., Jan., 61 (1): 41-9, 2008.

7- Petty P.M., Solomon M., Buchel E.W. and Tran N.V.: Gynecomastia: Evolving Paradigm of Management and Comparison of Techniques. Plast. Reconstr. Surg., May, 125 (5): 1301-8, 2010.

8- Lista F. and Ahmad J.: Power-Assisted Liposuction and the Pull-Through Technique for the Treatment of Gynecomastia. Plast. Reconstr. Surg., Mar., 121 (3): 740-7, 2008. 
9- Hammond D.C., Arnold J.F., Simon A.M. and Capraro P.A.: Combined Use of Ultrasonic Liposuction with the Pull-Through Technique for the Treatment of Gynecomastia. Plast. Reconstr. Surg., Sep., 112 (3): 891-5, 2003.

10- Kasielska-Trojan A. and Antoszewski B.: Gynecomastia Surgery-Impact on Life Quality: A Prospective CaseControl Study. Ann. Plast. Surg., Mar., 78 (3): 264-8, 2017.

11- Ridha H., Colville R.J.I. and Vesely M.J.J.: How happy are patients with their gynaecomastia reduction surgery? J. Plast. Reconstr. Aesthetic Surg., Nov., 62 (11): 14738, 2009.

12- Kasielska A. and Antoszewski B.: Surgical Management of Gynecomastia: An outcome analysis. Ann. Plast. Surg., Nov., 71 (5): 471-5, 2013.
13- Keskin M., Sutcu M., Hanci M. and Cigsar B.: Reduction of the Areolar Diameter after Ultrasound-Assisted Liposuction for Gynecomastia. Ann. Plast. Surg., 2017.

14- Rohrich R.J., Ha R.Y., Kenkel J.M. and Adams W.P.: Classification and management of gynecomastia: Defining the role of ultrasound-assisted liposuction. Plast. Reconstr. Surg., 2003

15- Graf R., Auersvald A., Costa Damasio R.C., Rippel R., De Araújo L.R.R., Camargo Bigarelli L.H., et al.: Ultrasound-assisted liposuction: An analysis of 348 cases. Aesthetic Plast. Surg., 2003.

16- Kazzazi F. and Malata C.M.: Application of the Lalonde (horizontal-only scar) breast reduction technique for correction of gynaecomastia in dark skinned patients. Gland. Surg., Jun., 8 (3): 287-93, 2019. 